\title{
Keanekaragaman Jenis Udang Air Tawar Di Sungai Tinombo Kecamatan Tinombo Kabupaten Parigi Moutong Provinsi Sulawesi Tengah
}

\author{
(Diversity Of Fresh Water Shrimp In River \\ District Tinombo Tinombo Parigi Moutong \\ District Sulawesi Province)
}

\author{
Rahmi $^{*}$,Annawaty, Fahri \\ Lab. Biologi DasarJurusan Biologi Fakultas MIPA, UniversitasTadulako, \\ Jl.Soekarno Hatta km 9 Tondo Palu Sulawesi Tengah
}

\begin{abstract}
The aim of this study is to determine thediversity of freshwater prawnsin Tinombo River, Parigi Moutong, Central Sulawesi Indonesia. Sampling was doneat16points which are spread are spread long the upstream and down stream of theriver. Specimens were preservedin $96 \%$ alcohol and deposited in Laboratory of Biology, Faculty of Basic Sciences Tadulako University and Laboratory of Crustacea, Division of Zoology, Research Center for Biology, LIPI, Cibinong. Identification of the specimens indicated that there are two species of freshwater prawns in Tinombo River, i.e. Macrobrachium austral and M. placidulum, both species belong to the Family Palaemonidae. Diversity index of freshwater-shrimps in the river is low. This low value in diversity index are not influenced byphysical and chemical environment factors.
\end{abstract}

Key words : Macrobrachium, fresh water prawns, Tinombo River, Sulawesi

\begin{abstract}
ABSTRAK
Penelitian ini bertujuan untuk mengetahui keanekaragaman jenis udang air tawar di Sungai Tinombo, Parigi Moutong, Sulawesi Tengah, Indonesia . Sampling dilakukan pada beberapa titik yang, tersebar pada bagian hulu sampai hilir Sungai. Spesimen yang diperoleh diawetkan dalam botol yang telah diisi alkohol $96 \%$. Pengamatan morfologi dan identifikasi spesimen dilakukan di Laboratorium Biologi Dasar FMIPA Universitas Tadulako. Spesimen disimpan di Laboratorium Biologi Dasar FMIPA Universitas Tadulako dan Laboratorium Crustacea, Divisi Zoologi Pusat Penelitian Biologi LIPI Cibinong. Hasil penelitian menunjukkan di Sungai Tinombo terdapat dua spesies udang air tawar yang termasuk dalam famili Palaemonidae genus Macrobrachium, yaitu M.australe dan M. placidulum. Indeks keanekaragaman jenis Macrobrachium pada Sungai Tinombo adalah tergolong rendah. Namun demikian, rendahnya keanekaragaman tersebut bukan di pengaruhi oleh faktor fisik dan kimia lingkungan perairan.
\end{abstract}

Kata kunci : Macrobrachium, udang air tawar, Sungai Tinombo, Sulawesi 


\section{LATAR BELAKANG}

Sungai merupakan salah satu bentuk ekosistem air tawar yang digunakan oleh berbagai organism sebagai habitatnya. Kondisi sungai mengalami perubahan aspek-aspek fisik dan kimiawi secara gradual dari bagian hulu ke hilir (Vannote dkk., 1980). Perubahan dapat terjadi karena beberapa anak sungai menyatu pada bagian hilir sungai, sehingga volume air bertambah dan induk sungai menjadi lebih luas (Soemarwoto dkk.,1980). Menurut Wooton (1991), area yang lebih luas sering memiliki variasi habitat yang lebih besar dibanding area yang sempit, sehingga semakin panjang dan lebar ukuran sungai semakin banyak pula jumlahspesies yang menempatinya.

Salah satu biota yang bisa ditemukan di perairan air tawar adalah udang yang merupakan salah satu anggota dari kelas Crustaceae, ordo Decapoda. Udang air tawar yang memiliki penyebaran luas adalah genus Macrobrachium yang terdiri dari 240 spesies.Sekitar 100 spesies anggota Macrobrachium tersebar di Asia Tenggara dan Asia Timur.Udang ini menghuni beberapa habitat air tawar seperti kolam, danau, rawa dan sungai (Wowor et al., 2009).

Menurut Murtidjo (1992), udang air tawar di Indonesia didominasi oleh dua famili, yaitu Palaemonidae dan
Atyidae. Anggota famili Palaemonidae yang paling banyak ditemukan di Indonesia adalah dari genus Macrobrachium. Anggota dari genus Macrobrachium. Siklus hidupnya dikelompokan menjadi dua, yaitu kelompok yang menyelesaikan seluruh siklus hidupnya di air tawar dan kelompok yang membutuhkan air laut atau air payau untuk menyelesaikan siklus hidupnya.

Keanekaragaman udang dalam suatu perairan menunjukkan kondisi lingkungan tersebut, apakah dapat mendukung atau tidaknya kelangsungan hidup suatu populasi jenis udang. Sifat fisik dan kimia perairan yang khas menunjukkan kondisi lingkungan yang bervariasi sehingga menyebabkan organisme yang hidup di perairan tersebut memiliki kekhasan pula (Supriharyono, 2000).

Udang air tawar mempunyai peranan penting dalam menjaga keseimbangan ekosistem. Salah satunya sebagai komponen mata rantai makanan. Udang berperan sebagai pakan bagi hewan akuatik yang lebih besar seperti ikan dalam mata rantai makanan. Selain itu juga berperan sebagai pemakan bangkai dan detritus di perairan. Rantai makanan akan terganggu jika kehilangan salah satu komponennya. Pelestarian udang air tawar menjadi penting dilakukan agar keseimbangan ekosistem dapat 
dipertahankan. Keberadaan berbagai jenis udang air tawar dalamsuatu perairanumum dapat meningkatkan kualitas kondisi lingkungan perairan tersebut (Taufik, 2011).

Salah satu sungai di Sulawesi yang dihuni oleh udang air tawar adalah sungai Tinombo yang terletak di Desa Tinombo Kecamatan Tinombo Kabupaten Parigi Moutong, namun hingga sejauh ini belum ada informasi ilmiah mengenai jenis-jenis udang air tawar apa saja yang terdapat di sungai tersebut. Oleh karena itu dilakukannya penelitian ini bertujuan untuk mengetahui keanekaragaman udang air tawar yang terdapat pada Sungai Tinombo, yang nantinya dapat bermanfaat dan menjadi sumber informasi mengenai biodeversitas udang air tawar di Sulawesi khususnya, dan di Indonesia pada umumnya.

Tujuan dari penelitian ini yaitu untuk mengetahui keanekaragaman jenis udang air tawar di Sungai Tinombo Kecamatan Tinombo Kabupaten Parigi Moutong Provinsi Sulawesi Tengah.

\section{BAHAN DAN METODE}

\section{Waktu dan Tempat}

Penelitian ini telah dilaksanakan pada bulan Mei hingga November 2015 di sungai Tinombo, Desa Tinombo dan Desa Lombok Kecamatan Tinombo, Kabupaten
Parigi Moutong, Provinsi Sulawesi Tengah. Identifikasisampel dilakukan di Laboratotium Biologi Dasar Fakultas MIPA universitas Tadulako.

Alat yang digunakan dalam penelitian ini adalah jaring, termometer, kertas $\mathrm{pH}$ meter, tali, botol, kamera, botol sampel, pinset, GPS (Global Positioning System), mikroskop stereo, dan alat tulis menulis, sedangkan bahan yang digunakan adalah udang air tawar, tissu, kertas label, kertas kalkir, dan alkohol $96 \%$.

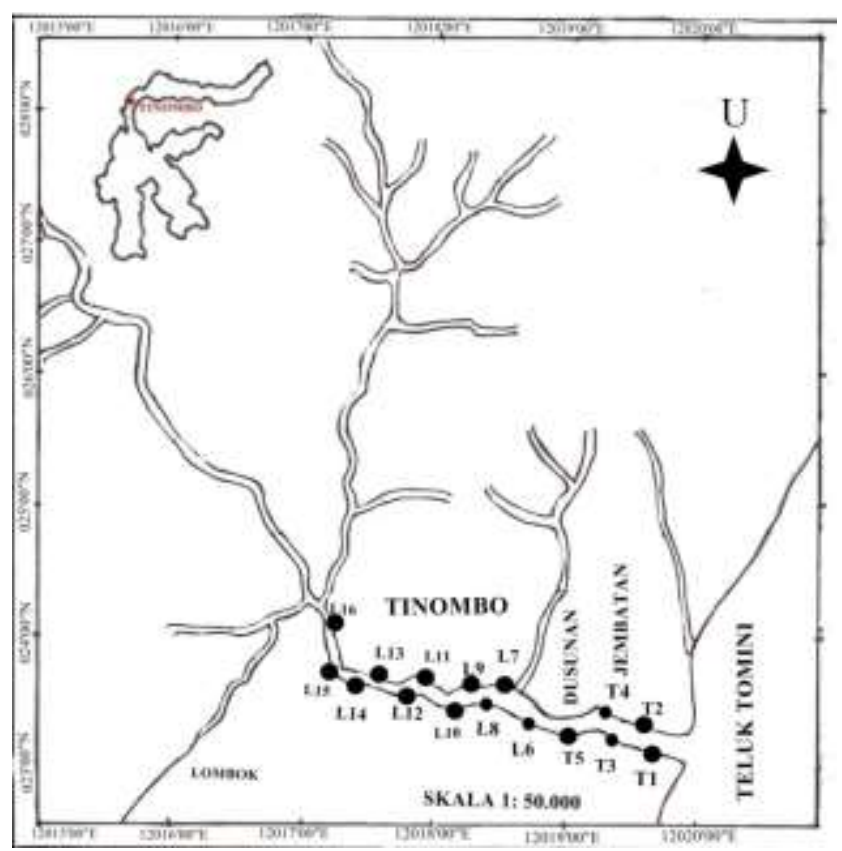

Gambar 1. Lokasi sampling di Sungai Tinombo (Peta dimodifikasi dari Peta RBI Lembar Palu Tahun 1991).

\section{PenentuanTitikdan Cara Pengambilan Sampel}

Penentuan titik pengambilan sampel dilakukan secara purposive dan ditandai dengan koordinat serta ketinggiannya dari permukaan laut pada peta dengan bantuan GPS. Pada penelitian ini, titik pengambilan 
sampel ditentukan sebanyak 16 titik (Gambar 1) . Sampling dilakukan pada setiap titik, dimana titik-titik tersebut terbagi pada bagian hulu sampai hilir sungaiTinombo dan Lombok di daerah Tinombo. Pengambilan sampel dilakukan dengan metode road sampling melawan arus sungai, yaitu merupakan metode pengambilan sampel dengan cara berjalan di setiap titik pengambilan sampel yang telah ditentukan untuk menangkap sampel.Kegiatan inidilakukan pada pagi hingga siang hari menggunakan hand net maupun tangan kosong. Sampel hasil tangkapan didokumentasi dalam keadaan segar kemudian diberi alkohol 96\% dan diberi label.

\section{Pengamatan Ekologi}

Pengamatan ekologi habitat udang dilakukan pada setiap titik pengambilan sampel. Pengamatan yang dilakukan meliputi vegetasi di lokasi sampling, yaitu substrat dasar sungai dilakukan dengan melihat dominasi pada dasar sungai, yaitu batu, pasir, atau lumpur. Penggukuran suhu air menggunakan termometer, Dissolved Oxygen (DO) dengan menggunakan consfor tipe C933, serta pengukuran kecepatan arus dengan menggunakan tali rapia dengan panjang 10 meter dan pelampung. Pengamatan arus sungai dilakukan dengan cara menghitung kecepatan waktu pelampung yang diikat dengan tali sepanjang 10 meter yang dialirkan di sungai, dengan ketentuan yaitu arus yang sangat lambat $(<0,10 \mathrm{~m} /$ detik $)$, lambat $(0,10-0,25 \mathrm{~m} /$ detik $)$, sedang $(0,25$ 0,50 $\mathrm{m} /$ detik), cepat $(0,50-1 \mathrm{~m} /$ detik $)$, dan sangat cepat (> $1 \mathrm{~m} /$ detik) (Welch dan Lindell, 1980).

\section{Identifikasi sampel}

Pengamatan morfologi dan identifikasi sampel dilakukan dengan menggunakan mikroskop stereo di Laboratorium Biologi Dasar FMIPA UNTAD. Spesimen disimpan di Laboratorium Biologi Dasar FMIPA Universitas Tadulako dan Laboratorium Crustacea, Divisi Zoologi Pusat Penelitian Biologi LIPI Cibinong. Identifikasi dilakukan berdasarkan bentuk, ciri taksonomi, ukuran tubuh, mengikuti kunci identifikasi Crustacea Wowor et al.,(2004). Carapace sleng diukur mulai dari bagian posterior orbital marjin sampai bagian posterior carapace. Telur diukur menggunakan micrometer dan diamati di bawah mikroskop.

\section{Penentuan indeks keanekaragaman (H')}

Keanekaragaman ditentukan berdasar rumus Shanon Wiener (Magurran, 1997).

$$
\mathrm{H}^{\prime}=-\Sigma \mathrm{pi} \text { Inpi, dimana } \mathrm{pi}=\mathrm{ni} / \mathrm{N}
$$

Keterangan:

$\mathrm{H}^{\prime}$ : Nilai indeks keanekaragaman

$p_{\mathrm{i}} \quad$ : Proporsi jumlah individu spesies ke-i (ni) terhadap total individu 
$\mathrm{N}$ : Jumlah total individu semua spesies

ni : Jumlah individu ke-i

Berdasarkan indeks keanekaragaman jenis menurut Krebs (1985), didefinisikan sebagai berikut:

a. Nilai $H^{\prime}<1,5$ berarti keanekaragaman spesies pada suatu transek rendah

b. Nilai H' 1,5-3,5 berarti keanekaragaman spesies pada suatu transek sedang

c. Nilai H'>3,5 berarti

keanekaragaman spesies pada suatu transek tinggi.

\section{HASIL DAN PEMBAHASAN}

Udang air tawar yang ditemukan di Sungai Tinombo terdiri dari dua spesies yang termasuk dalam famili Palaemonidae, genus Macrobrachium, yaitu M.australe dan M. placidulum.Sebanyak 109individu yang didapatkan di Sungai Tinombo yang terdiri dari 82 individu M.australe dan 27 individu M. placidulum.

\section{Morfologi dan Distribusi M. australe}

Macrobrachium australe memiliki ciri morfologi, antara lain gigi yang tidak tersebar merata pada ujung anterior, biasanya terdapat celah berupa bagian yang tidak bergerigi pada bagian dorsal anterior atau memiliki gigi di ujung rostrum (apical tooth) (Gambar 2); pada bagian rostrum terdapat gigi dorsal 4-12/1-3 dengan gigi ventral 2-4; panjang carapace berkisar 6 -
20 mm.peripodkedua memiliki ukuran chela dua kali panjang merus, panjang carpus lebih pendek dari panjang chela, merus sedikit lebih panjang daripada carpus, panjang ischium lebih pendek dari panjang merus; pada ujung postrior telson tidak melewati posterolateral spine. Carpus lebih pendek dari merus (Gambar 3). Secara umum, morfologi $M$. australe dari Sungai Tinombo tidak jauh berbeda dengan spesiemen yang telah dideskripsi oleh Chace dan Bruce, (1993) meskipun terdapat perbedaan pada peripods kedua yaitu pada perbandingan panjang carpus dan merus. Apabila pada M.australe dari Sungai Tinombo memiliki ukuran merus yang sedikit lebih panjang daripada carpus. Tetapi pada specimen yang dideskripsi oleh Chace dan Bruce (1993), carpusnya berukuran lebih pendek dari pada merus.

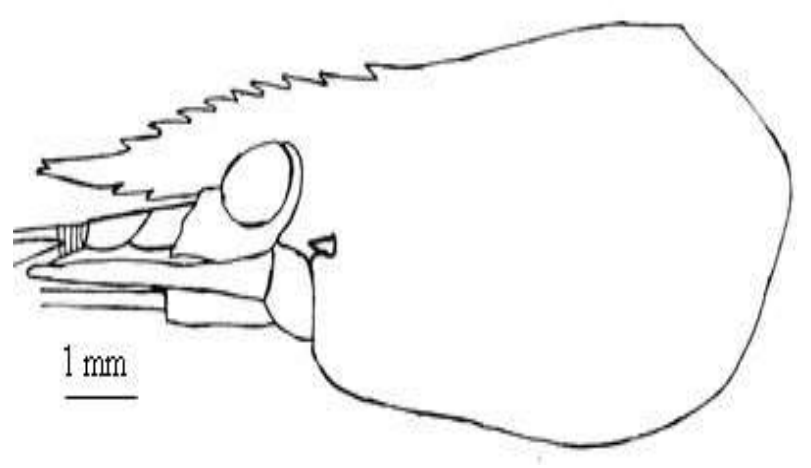

Gambar 2. Morfologi Carapace M. Australe 


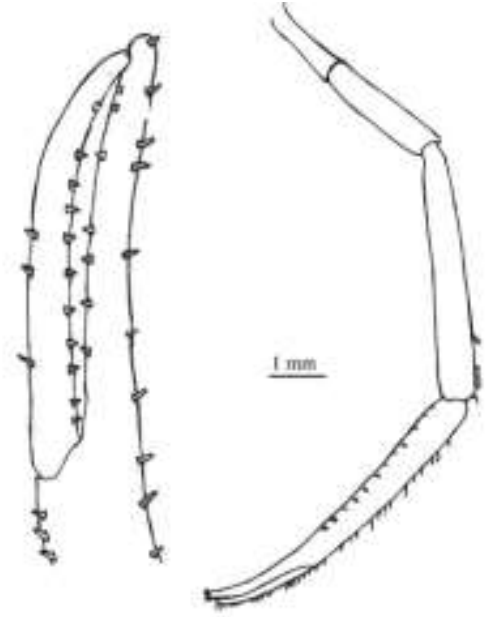

Gambar 3. Morfologi Pereiopod kedua $M$. australe.

Macrobrachium australe memiliki ukuran telur yang berkisar antara 0,31-1,0 mm. Menurut Wowor et al. (2009) ukuran telur yang demikian termasuk dalam kategori Macrobrachium bertelur kecil, sehingga dalam siklus hidupnya, spesies tersebut masih memerlukan air laut atau air payau untuk perkembangan larvanya menjadi juvenil.

Macrobrachium australe awalnya diketahui penyebarannya di Madagaskar dan Seychelles, Samudera Hindia hingga Taiwan, Pilipina, Indonesia, dan Kepulaun Pasifik. Selain itu juga ditemukan disepanjang pulau Marshall di Utara Pasifik dan pulau Marquesas Pasifik Selatan (Chace dan Bruce, 1993).

Morfologi dan Distribusi M. placidulum

Macrobrachium placidulum memiliki ciri morfologi antara gigi yang tersebar merata pada ujung anterior dan tidak terdapat bagian yang tidak bergigi; pada bagian rostrum terdapat gigi dorsal 48/1-3, dan gigi ventral 1-3; panjang carapace5 mm- $23 \mathrm{~mm}$ (Gambar 4); pereiopod kedua memiliki ukuran chela lebih panjang daripada carpus, carpus lebih panjang dari pada merus, panjang ischium kurang dari panjang merus (Gambar 5).

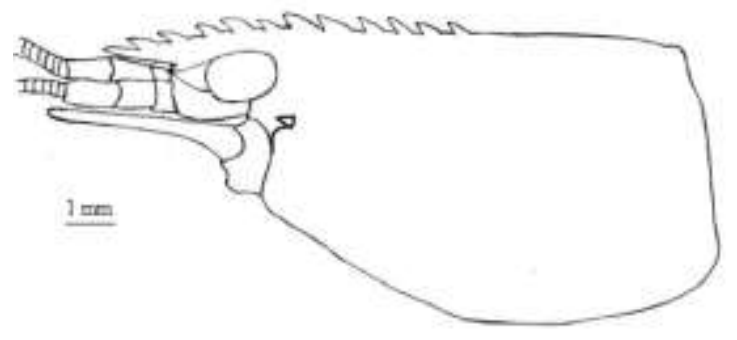

Gambar 4. Morfologi Carapace M. placidulum

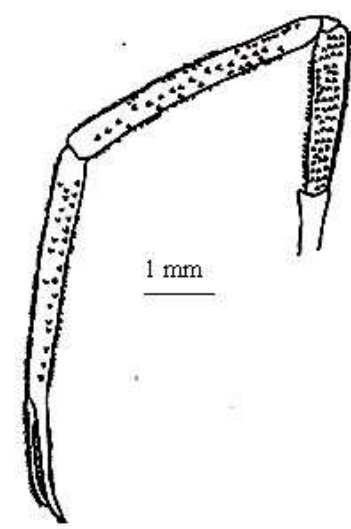

Gambar 5. Morfologi Pereiopod kedua $M$. placidulum

Macrobrachium placidulum memiliki ukuran telur berkisar antara 0,30-1,0 mm. Menurut Wowor et al. (2009), telur Macrobrachiumyang berukuran kurang dari $1.0 \mathrm{~mm}$ termasuk dalam kategori Macrobrachium bertelur kecil, yang menunjukkan bahwa dalam siklus hidupnya masih memerlukan atau membutuhkan air 
laut atau air payau untuk perkembangan larvanya menjadi juvenil.

Spesies Macrobrachium placidulum diketahui dari Indonesia bagian Timur, Makassar dan Papua Nugini, dari New Hanover di kepulauan Bismarck, Palau, dan Fiji (Chace dan Bruce, 1993).

\section{Indeks Keanekaragaman}

Nilai keanekaragaman jenis Macrobrachium pada Sungai Tinombo adalah 0,55. Nilai ini tergolong rendah menurut kriteria Krebs (1985)

Kedua spesies Macrobrachium yang ditemukan di Sungai Tinombo memiliki perbedaan distribusi. $M$. australe merupakan spesies yang paling banyak penyebarannya dan ditemukan pada setiap stasiunyaitu pada keadaan air dengan kecepatan arus berkisar antara 0,24-1,1 $\mathrm{m} /$ detik (arus sedang-sangat deras), sedangkan $M$. placidulum ditemukan pada keadaan air yang tenang dengan kecepatan arus berkisar antara 0,24-0,5 m/detik (arus sedang). Kedua spesies ini memiliki habitat pada substrat perairan yang berbatu berlumpur serta berlumut.

\section{Indeks Keanekaragaman jenis}

Nilai indeks keanekaragaman yang didapatkan dari hasil pengamatan termasuk kategori rendah, yaitu $\mathrm{H}^{\prime}=0,55$. Jika dilihat dari faktor kimia perairan untuk kehidupan udang air tawar, maka terdapat beberapa faktor yang mendukung untuk kehidupan atau kelangsungan hidup udang air tawar di Sungai Tinombo yaitu suhu, $\mathrm{pH}$ dan DO. Suhu memiliki kisaran antara 26 $30^{\circ} \mathrm{C}$ dan tergolong optimal bagi kehidupan udang sehingga dapat mendukung kelangsungan hidupnya. Menurut New (2002), kisaran suhu yang baik untuk pertumbuhan dan kehidupan udang air tawar terletak pada suhu $26-31^{\circ} \mathrm{C}$.

Tingkat keasaman $(\mathrm{pH})$ yang didapatkan dari masing-masing stasiun adalah 7, yang dapat mendukung kehidupan udang tersebut. Hal ini dapat terjadi karena pada stasiun tersebut memiliki kisaran suhu yang baik dan kandungan oksigen yang tinggi. Silalahi (2009) menyatakan bahwa nilai $\mathrm{pH}$ dipengaruhi oleh suhu, kandungan oksigen, ion-ion dan aktivitas biologi. Selanjutnya menurut New (2002) pH optimum untuk udang air tawar yaitu berkisar antara 7 sampai 8,5 .

Pengukuran DO juga bertujuan melihat sejauh mana badan air mampu menampung biota air seperti udang air tawar dan mikroorganisme lainnya. Menurut New (2002), kandungan DO yang mendukung bagi udang air tawar yaitu berkisar antara 3-7 mg/l, sedangkan DO yang didapatkan memiliki kisaran 5,22 $10,2 \mathrm{mg} / \mathrm{l}$. Hasil pengukuran ini sedikit lebih tinggi daripada yang disebutkan dalam literatur. 


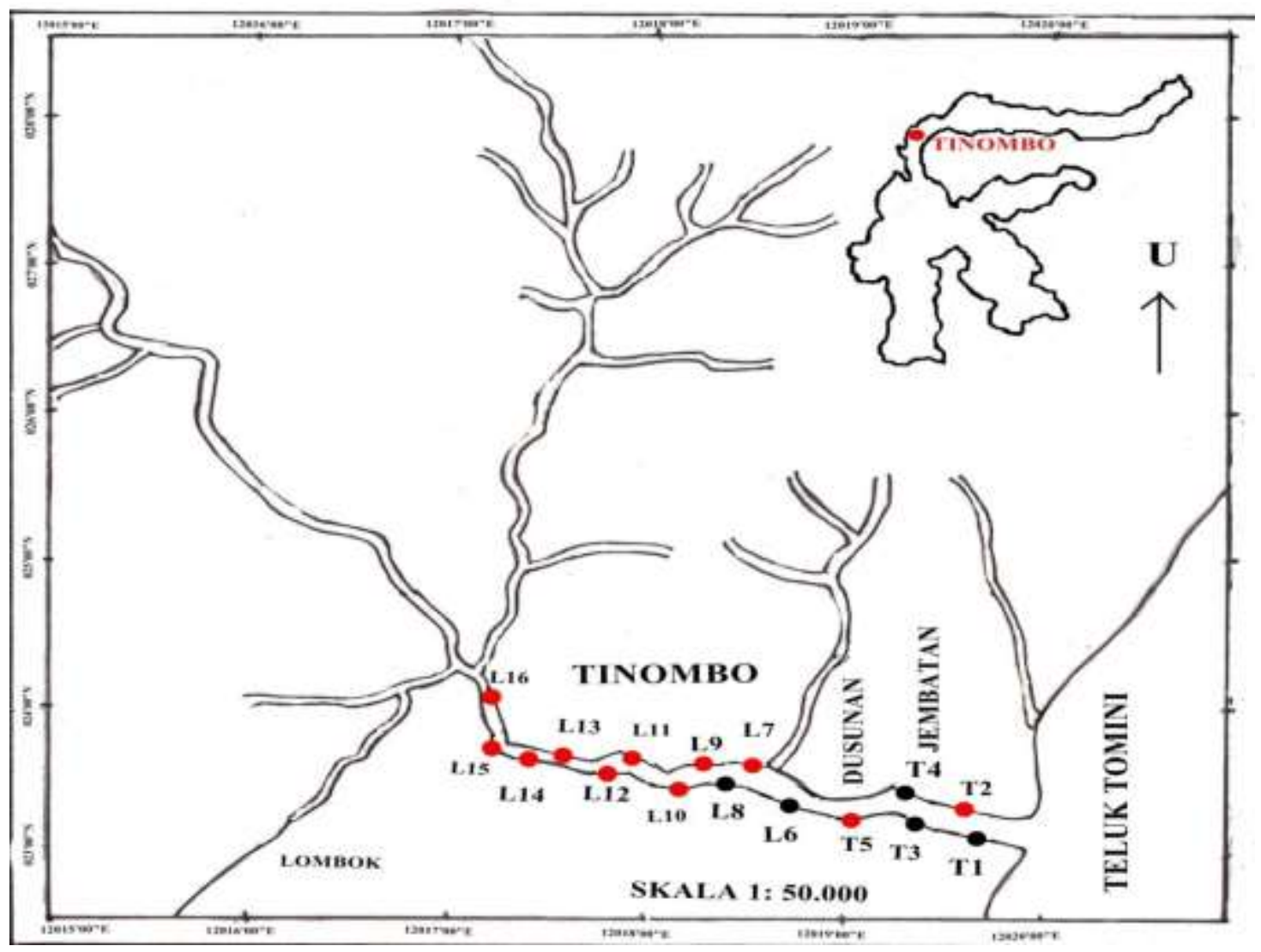

Keterangan:

Macrobrachium australe

Macrobrachium australe dan M. placidulum

Tabel 1. Distribusi spesies Macrobrachiumdi Sungai Tinombo

\begin{tabular}{|c|c|c|c|c|c|c|c|c|}
\hline \multirow{2}{*}{ Area } & \multirow{2}{*}{ Stasiun } & \multirow{2}{*}{$\begin{array}{l}\text { Arus } \\
\text { air } \\
\mathrm{m} / \mathrm{dt}\end{array}$} & \multirow{2}{*}{ Substrat } & \multirow{2}{*}{$\begin{array}{c}\text { Suhu air } \\
{ }^{0} \mathrm{C}\end{array}$} & \multirow{2}{*}{$\mathrm{pH}$} & \multirow{2}{*}{ DO } & \multicolumn{2}{|c|}{ Jumlah individu } \\
\hline & & & & & & & M. australe & $M$ placidulum \\
\hline \multirow[t]{5}{*}{ Tinombo } & 1 & 1,1 & Batu berlumpur & 28 & 7 & 6,68 & 10 & - \\
\hline & 2 & 0,4 & Batu berlumpur & 28 & 7 & 8,05 & 13 & 2 \\
\hline & 3 & 1,01 & Berbatu & 26 & 7 & 10,2 & 8 & - \\
\hline & 4 & 0,59 & Batu berlumpur & 28 & 7 & 6,52 & 3 & - \\
\hline & 5 & 0,39 & $\begin{array}{l}\text { Berbatu } \\
\text { berlumpur+berlumut }\end{array}$ & 28 & 7 & 6,41 & 7 & 1 \\
\hline \multirow[t]{12}{*}{ Lombok } & 6 & 0,61 & Berbatu belumut & 28 & 7 & 6,25 & 5 & - \\
\hline & 7 & 0,5 & $\begin{array}{l}\text { Berbatu } \\
\text { berlumut+berlumpur }\end{array}$ & 28 & 7 & 6,07 & 6 & 1 \\
\hline & 8 & 0,55 & Berbatu & 27 & 7 & 5,89 & 3 & - \\
\hline & 9 & 0,35 & Berbatu & 27 & 7 & 5,71 & 2 & 1 \\
\hline & 10 & 0,42 & Berbatu berlumpur & 26 & 7 & 5,22 & 1 & 2 \\
\hline & 11 & 0,38 & $\begin{array}{l}\text { Berlumpur+berbatu+ } \\
\text { Berlumut }\end{array}$ & 27 & 7 & 7,01 & 7 & 4 \\
\hline & 12 & 0,33 & Batu berlumut & 27 & 7 & 6,32 & 2 & 4 \\
\hline & 13 & 0,34 & Batu berlumut & 28 & 7 & 6,22 & 3 & 3 \\
\hline & 14 & 0,3 & Berbatu & 26 & 7 & 7,14 & 3 & 2 \\
\hline & 15 & 0,26 & Berbatu & 28 & 7 & 7,10 & 4 & 4 \\
\hline & 16 & 0,24 & Batu berlumut & 26 & 7 & 6,55 & 5 & 3 \\
\hline & & & Total & & & & 82 & 27 \\
\hline
\end{tabular}


Dengan melihat faktor kimia perairan di Sungai Tinombo (Tabel 1) yang sangat mendukung bagi kelangsungan hidup udang air tawar, maka rendahnya keanekaragaman udang air tawar di Sungai Tinombo tidak disebabkan oleh faktor kimia perairan tersebut namun diduga disebabkan oleh faktor lain yang tidak kita ketahui.

Macrobrachium australe ditemukan pada bagian sungai yang memiliki arus deras maupun lambat, yaitu memiliki kisaran arus 0,24-1,1 m/detik dengan substrat berbatu, berlumpur serta berlumut. Hal ini sesuai dengan morfologi udang tersebut yang memiliki carpus berbentuk panjang dan besar pada periopod kedua, sehingga mampu bertahan pada keadaan arus deras maupun lambat dan ditemukan pada setiap stasiun.

Sedangkan $M$. placidulum ditemukan pada sungai yang berarus sedang, memiliki kisaran arus 0,24-0,5 $\mathrm{m} /$ detik dengan substrat berbatu, berlumpur dan berlumut. Hal ini sesuai dengan morfologi udang tersebut yang memiliki carpus berbentuk panjang dan langsing pada periopods kedua. Pada penelitian ini, M. placidulum tidak ditemukan pada kecepatan arus di atas $0,55 \mathrm{~m} /$ detik (arus deras).

Berdasarkan hasil penelitian ini didapatkan dua spesis udang air tawar dari famili

Palaemonidae, genus
Macrobrachium yaitu $M$. australe dan $M$. placidulum. Keanekaragaman jenis udang air tawar di Sungai Tinombo tergolong rendah namun tidak di pengaruhi oleh faktor fisik dan kimia lingkungan sungai.

\section{UCAPAN TERIMA KASIH}

Penulis mengucapkan terima kasih kepada laboranBiologi Dasar FMIPA UNTAD yakni Sami Bukang S.P, danNurulAisyahS.Si. Terima kasih juga penulis ucapkan kepada Tri Mulyati danYayuk Pratiwi yang sudah membantu proses identifikasi. Penulis juga berterima kasih kepada Hasmah, Faidah, Putri Suria Ningsi, Donny Saputra S.Si, Sultan Harmain dan Andika Harmain yang sudah membantu proses sampling.

\section{DAFTAR PUSTAKA}

Chace, F.A. Jr. and Bruce, A.J. 1993. The caridean shrimps (Crustacea: Decapoda) of the Albatross Philippine expedition, 1907-1910, Part 6: Superfamily

Palaemonoidea.Smithsonian Contributions in Zoology. 543: 1152.

Krebs, C. J. 1985. Ecology: The Experimental Analysis of Distribution and Abudance. Third Edition, Harper $\&$ Row, Publisher Inc. New York.

Magurran, A.E. 1987.Ecological Diversity and its Measurement. New Jersey: Princeton University Press.

Murtidjo, B.A.1992. Budidaya Udang Galah. Yogyakarta. Kanisus. 
New. M.B. 2002. Farming Freshwater Prawns. A Manual for The Culture of The Giant River Prawn (Macrobrachium rosenbergii). Food and Agriculture Organization. FAO Fisheries Tecnical Paper 428. Roma.

Vannote.R.L. Minshall. G.W. Cummins. K.W. Sedell. J.R and Cushing. C.E. 1980.The River Continuum Concept. Canadian Journal of Fish Aquatic Sciience37: 130-137.

Silalahi. J. 2009. Analisis Kualitas Air dan Hubungannya dengan Keanekaragaman Vegetasi Akuatik di Perairan Balige Danau Toba. Tesis. Sekolah Pascasarjana. USU: Medan.

Soemarwoto, Gandjar, OI, Guhardja, E, Nasution, AH, Soemartono, S dan Somadiharta, LK. 1980. Biologi Umum II. Gramedia, Jakarta

Supriharyono.2000. Pelestarian dan Pengelolaan sumber daya alam di wilayah pesisir tropis. Jakarta. Gramedia.

Taufik. 2011. Keanekaragaman udang air tawar di danau Kerinci Provinsi
Jambi. Tesis. Fakultas Matematika dan Ilmu Pengatahuan Alam. Institut Pertanian Bogor.

Welch. E. B and Lindel. T. 1980. Ecological Effects Of Waste Water. Cambridge University Press. Cambridge.

Wooton, J. 1991. Ecology of Teleost Fishes, Chapman and Hall. New York.

Wowor, D.Cai. Y. Ng. P.K.L. 2004. Crustacea: Decapoda, Caridea. Di dalam: Yule CM.Sen YH.editor. Freshwater Invertebrata Of The Malaysian Region. Kuala Lumpur: AkademiSains Malaysia. 337-357.

Wowor, D. Muthu. V. Meier. R. Balke. M. Cai.Y.Ng. P.K.L. 2009.Evolution of life history traits in asian freshwater prawns of genus Macrobrachium (Custacea: Decapoda: Palaemonidae) based on multilocus molecular phylogenetic analysis. $\mathrm{Mol}$ Phylogenetic and Evol 52: 340-350. 